\title{
Avaliação in Vitro do Potencial Probiótico de Queijo Coalho Caprino Adicionado de Lactobacillus Rhamnosus
}

\section{Fernanda Rodrigues Leite Rolim (I), Karina Maria Olbrich dos}

Santos (IV), Samuel Carneiro de Barcelos (III), Thais Santana Ribeiro (I), Maria Lúcia da Conceição (I), Maria Elieidy Gomes de Oliveira (II), Marciane Magnani (I), Rita de Cássia Ramos do Egypto Queiroga (I)

(I) UFPB - Universidade Federal da Paraíba (Cidade Universitária, s/n - Castelo Branco João Pessoa - PB), (II) UFCG - Universidade Federal de Campina Grande (Av. Aprígio Veloso, 882, bairro do Bodocongó Campina Grande, PB), (III) IFCE - Instituto Federal do Ceará (Av. Treze de Maio, 2081 - Benfica, Fortaleza CE, 60040-531), 4 Embrapa - Embrapa Caprinos e Ovinos (Estrada Sobral, km 4, Sobral - CE, 62100-000)

\section{Resumo}

Produtos probióticos são alimentos adicionados de culturas de microorganismos que atuam como agentes tecnológicos e como agentes terapêuticos. Os alimentos são considerados como um veículo ideal para o fornecimento de probióticos ao trato gastrointestinal humano pelo efeito protetor sobre as cepas probióticas durante a passagem até o seu local de ação, o intestino. $O$ presente trabalho analisou a sobrevivência de uma nova cepa de L. rhamnosus adicionado ao queijo tipo coalho caprino quando exposto às condições simuladas do trato gastrointestinal. Para tanto, utilizou-se uma câmara de incubação a $37^{\circ} \mathrm{C}$ com agitação mecânica para simular a temperatura do corpo humano e os movimentos peristálticos, com intensidades semelhantes a cada compartimento digestivo. Cada condição foi simulada adicionando-se em $25 \mathrm{~g}$ de amostra de queijo: solução de saliva (1- $\alpha$-amilase) e $\mathrm{NaHCO} 3$ a $0,1 \mathrm{M}$ para ajuste do $\mathrm{pH}$ em 6,9 , com agitação por 2 minutos, simulando a mastigação; solução de pepsina e $\mathrm{HCl}$ a $1 \mathrm{M}$ para gradativo ajuste do $\mathrm{pH}$ até 2 , por 90 minutos, simulando o esôfago-estômago; solução intestinal (pancreatina e sais biliares) e NaHCO3 a 0,1M para ajuste do pH em 5,0, para o duodeno; solução de

\footnotetext{
Referência:

Fernanda Rodrigues Leite Rolim, Karina Maria Olbrich dos Santos, Samuel Carneiro de Barcelos, Thais Santana Ribeiro, Maria Lúcia da Conceição, Maria Elieidy Gomes de Oliveira, Marciane Magnani, Rita de Cássia Ramos do Egypto Queiroga. Avaliação in Vitro do Potencial Probiótico de Queijo Coalho Caprino Adicionado de Lactobacillus Rhamnosus. In: Anais do 12 Congresso Latinoamericano de Microbiologia e Higiene de Alimentos - MICROAL 2014 [= Blucher Food Science Proceedings, num.1, vol.1]. São Paulo: Editora Blucher, 2014.

DOI 10.5151/foodsci-microal-220
} 
NaHCO3 a 0,1M para ajuste do pH em 6,5 na etapa do íleo. A contagem de células viáveis do probiótico em cada condição foi expressa em log das unidades formadoras de colônias por cada grama de queijo (log de UFC/g) e submetida à análise de variância (ANOVA) e teste de média de Tukey a $5 \%$ de significância $(\mathrm{p}<0,05)$. Ao final da digestão, houve manutenção da contagem de células viáveis $(6,99 \log \mathrm{UFC} / \mathrm{g})$ em relação à determinada antes da exposição às condições bucais $(6,89 \log \mathrm{UFC} / \mathrm{g})$. A capacidade de tolerar o estresse digestivo é uma das propriedades mais importantes para a incorporação bem sucedida de probióticos em alimentos. Diversos estudos com diferentes variedades de queijos, concluíram que o queijo pode oferecer algumas vantagens em relação a outros produtos lácteos. Em comparação com iogurte e leites fermentados, a capacidade de tamponamento é mais elevada no queijo, pelo $\mathrm{pH}$ mais elevado, maior teor de gordura e matriz sólida que podem melhorar a sobrevivência de bactérias no ambiente do estômago e intestino. A partir disso, constatou-se que o queijo de coalho pode ser viável em carrear a nova cepa de L. rhamnosus ao intestino sob condições simuladas do trato gastrointestinal.

Palavras-Chave: Alimentos Funcionais, Lácteos, Micro-organismos Agência de Fomento: Embrapa 